\title{
Formação de professores na perspectiva freireana: dizer o mundo e aprender/ensinar o mundo
}

Teacher training in freire's perspective: saying the world and learning/ teaching the world

Silvana Aparecida Pin* Universidade Regional Integrada do Alto Uruguai e das Missões

Arnaldo Nogaro** Universidade Regional Integrada do Alto Uruguai e das Missões

Cênio Back Weyh***

Universidade Regional Integrada do Alto Uruguai e das Missões

Resumo O presente estudo tem por objetivo refletir sobre a formação de professores a partir do pensamento de Freire, a fim de perceber indicativos que levem o educador a desenvolver uma educação libertadora por meio da práxis transformadora. A pesquisa realizada foi de caráter bibliográfico. Destaca-se a educação dialógica e a práxis social como desafios permanentes ao educador que deseja colaborar para uma transformação do mundo a partir de sua prática pedagógica. $\mathrm{O}$ algo a mais que o professor precisa para uma metodologia exitosa é sua própria libertação e seu trabalho na libertação de seus educandos. Para isso, ele conta com o poder da palavra, não apenas a palavra falada, mas a que se pode usar de muitas formas, como instrumento essencial no ensino/ aprendizagem para dizer e transformar o mundo.

PALAVRAS-CHAVE: Educação dialógica; Paulo Freire; Formação de professores.

Abstract This study aims to reflect on the training of teachers based on the Freire's conceptions in order to perceive indicatives that can lead the educator to develop a liberating education through transformative praxis. The research was of bibliographical character. The dialogical education and social praxis are highlighted as permanent challenges to the educators who wish to contribute to a world transformation from their practice. Something else that the teachers need for a successful methodology is their own liberation and work in their students'liberation. For this, they rely on the power of the word, not just the spoken word, but that can be used in many ways, as an essential tool in teaching/learning to say and change the world.

KEYWORDS: Dialogical education; Paulo Freire; Teacher training. 


\section{Provocando o pensamento}

Ser professor constitui-se em uma proposta para espíritos empreendedores, brilhantes, criativos e inquietos. Com essa afirmação, entende-se que a educação é compromisso desafiador, de responsabilidade pela vida, pela formação de pessoas humanas que estão principiando a conhecer o mundo e a dar-se conta das possibilidades abertas para viver a incrível aventura da existência. Nessa perspectiva, entende-se que o educador possui um encargo relacionado com a formação de crianças, adolescentes, jovens e adultos, e, por conseguinte, com a transformação das realidades que o cercam. Assim, não se pode admitir determinadas falácias de noticiários e propagandas eleitorais que, quando lhes convém, consideram a profissão docente como sendo de grande relevância. Nessas ocasiões, fica a dúvida de qual seja a intenção subjacente às súbitas mudanças quanto à valorização da classe docente.

Apreciar a profissão docente demanda, de forma real e concreta, colocar esse serviço no lugar que the é devido, pois somente a partir de uma cultura de valorização do humano e da vida, de educadores e educandos, pode-se desenvolver uma educação libertadora que conduza a uma práxis transformadora. Do ponto de vista do pensamento freireano, anuncia-se sempre a primazia da vida a ser vivida com dignidade e humildade, com altivez e serenidade, com alegria e compromisso, pautados pela ética, por valores que dão voz aos "demitidos da vida"1, que conferem espaço a todos quantos habitam este planeta. É o que autor chama de "biofilia" (FREIRE, 2011), entendendo com essa palavra a humanização do ser humano e a prioridade da vida.

O presente estudo tem por objetivo refletir sobre a formação de professores a partir do pensamento de Freire, a fim de perceber indicativos que habilitem o educador a desenvolver uma educação libertadora através da práxis transformadora. A pesquisa realizada foi de caráter bibliográfico, consultando-se algumas obras do referido autor e trazendo ao diálogo outros autores contemporâneos que discutem a formação de professores. Destacam-se a educação dialógica e a práxis social como desafios permanentes ao educador que deseja colaborar para a transformação do mundo, a partir de sua prática pedagógica. $\mathrm{O}$ algo a mais que o professor precisa para uma prática que seja excelente é sua própria libertação e seu trabalho na libertação para com os educandos. Para isso, conta com o poder da palavra ${ }^{2}$ como instrumento essencial no ensino/ aprendizagem, para dizer e transformar o mundo.

\section{Formação de professores na ótica freireana}

A formação de professores no Brasil passou por transformações de diferentes naturezas e, entre um projeto e outro, melhorou significativamente quando se pensa na ampliação do acesso à Educação Superior através de políticas públicas que incentivam o ingresso na carreira da educação. Dentre essas políticas pode-se referir o Programa Institucional de Bolsa de Iniciação à Docência - PIBID que, na formação inicial dos cursos de licenciatura, oportuniza aos graduandos contato com as realidades escolares, otimizando sua qualificação como profissionais da educação. 
Merece destaque, também, o Programa Nacional de Formação de Professores da Educação Básica - PARFOR, enquanto incentivo aos professores que ainda não têm um curso de graduação, ou que atuam em áreas diferentes de sua formação inicial. Além disso, podem-se citar outras políticas de aperfeiçoamento aos profissionais da educação como: o Pacto Nacional pelo Fortalecimento do Ensino Médio, o Pacto Nacional pela Alfabetização na Idade Certa, dentre outras políticas desenvolvidas por Estados e municípios. Todas essas oportunidades, disponibilizadas aos docentes são formas de incentivar a qualificação e atender às demandas oriundas dos novos cenários da educação.

No cotidiano escolar, percebem-se deficiências na educação e na formação dos educadores. Então, surgem algumas perguntas: o que ainda falta? Qual o problema que ainda não foi solucionado para que a educação, finalmente, avance e responda às necessidades do país? Existe uma pedagogia que responda às profundas necessidades da natureza humana? Podem os docentes dar conta dessa tarefa? Como encarar os inúmeros problemas de organização do ambiente escolar, de gestão, da falta de profissionais nas escolas, de incentivo e valorização salarial da carreira docente? $\mathrm{O}$ que precisa ser conservado e o que precisa ser mudado na educação brasileira?

A complexidade das questões remete à dificuldade de encontrar soluções. Num tempo em que não se conhece mais o sentido de uma verdadeira tradição, fica difícil falar em valores perenes, que devem ser cultivados nos núcleos familiares e aperfeiçoados nos ambientes escolares. Contudo, soluções provisórias não resolvem problemas complexos. Frutos da superficialidade da pós-modernidade, alunos e professores não possuem a segurança de um método que lhes dê a certeza de estar no caminho certo. E por não haver qualquer segurança, também, não há a serenidade de aceitar com espírito novo o que não precisa ser mudado porque faz parte da essência humana. Assim, em um ambiente marcado por extravagâncias e excessos, por descobertas maravilhosas e promissoras de uma vida feliz e perfeita estão, à mercê de seus frágeis "barquinhos", educadores e educandos embalados pelos ventos de teorias e práticas tão sedutoras, quanto contraditórias.

Nessa perspectiva, entende-se o pensamento de Franca, ao falar sobre o sentido da educação:

[...] educar não é formar um homem abstrato intemporal, é preparar o homem concreto para viver no cenário deste mundo. As mudanças profundas neste cenário, acentuando novas exigências e focalizando novos ideais, refletem-se nos métodos e nos programas destinados a preparar as gerações que sobem para as necessidades imperiosas da vida. (FRANCA, 1952, p. 75).

Educar é formar o ser humano concreto para a singularidade da vida. A multiplicidade de ideias, teorias, métodos e promessas de mudança não é privilégio do século 21, mas uma particularidade que acompanha a humanidade desde o princípio de sua existência. Ante aos desafios imanentes à profissão docente, Freire (2009) denuncia com raiva e indignação aquilo que entende como injusto e desumano, produto da lógica da opressão e da dominação dos poderosos, em relação aos mais fracos e oprimidos pelo sistema neoliberal e capitalista. Ao mesmo tempo, procura dar res- 
postas aos problemas encontrados no sistema educacional, anunciando com amor e dedicação a possibilidade de um mundo mais justo e humano, pautado na igualdade e no respeito à diversidade.

Freire foi mentor de uma teoria ético-crítico-libertadora (FREIRE, 2009), resultado de seu caráter sensível e inteligente, envolvido e engajado em seu ambiente de convivência e do que fervilhava pelo mundo, sempre dando especial atenção às formas opressoras utilizadas para manipular o povo. Sua vasta experiência e seu conhecimento de outros países, também, contribuíram para que suas teorias e práticas educacionais surtissem efeitos concretos. Dessa forma, ele tem uma compreensão crítica da educação e a preocupação de dar ao ser humano o lugar que lhe compete, a condição de sujeito e de ser em construção. Assim, cabe destacar algumas características da educação libertadora que dá conta da formação do ser humano, chamado a ser sujeito de sua própria existência.

\section{Educação dialógica}

O diálogo na educação libertadora apresenta-se como a metodologia que institui no centro do processo educativo a transformação do aluno e do professor em protagonistas de sua formação e da mudança da sociedade. "Dialogar é interagir com o outro, respeitá-lo em sua forma de ser, é acolher suas necessidades e dispor-se a construir uma nova história junto com o outro, a partir da história que cada um já traz consigo." (PIN, 2014, p. 79). Assim, educar torna-se uma forma de agir no mundo e transformá-lo e não apenas um processo passivo de adquirir conhecimentos, como acontece na "educação bancária".

Nesse processo, é fundamental o que Freire chama de "pedagogia da pergunta”. Através da problematização dos conceitos e dos conteúdos, a serem ensinados, suscita-se nos educandos a curiosidade epistemológica, a necessidade de buscar sempre mais, de apropriar-se do conhecimento e socializá-lo com os demais. "Nessa perspectiva, o diálogo é a força que impulsiona o pensar crítico-problematizador em relação à condição humana no mundo. Através do diálogo podemos dizer o mundo segundo nosso modo de ver." (ZITKOSKI, 2008, p. 130). A formação para o pensar crítico e problematizador é uma necessidade urgente. Fala-se de trabalho profundo e sustentado por teorias pedagógicas comprometidas com a transformação da educação, não é o que se constata em muitas escolas com as propaladas palestras motivacionais.

A capacidade de "dizer o mundo" subentende que já se compreendeu o mundo, concebido como o objeto do conhecimento. Neste processo, é essencial perguntar, criar dúvidas, problemas, necessidade de busca de respostas. Assim, vai se desenvolvendo a prática de não aceitar as coisas como elas são, mas de criar senso crítico que questiona e duvida para saber mais e construir-se, na consciência de que existem condicionamentos históricos de opressão, que podem e devem ser mudados. Fiori (1980) absorve muito bem esta questão ao escrever que a prática da liberdade só encontrará adequada expressão numa pedagogia em que o oprimido tenha condições de, reflexivamente, descobrir-se e conquistar-se como sujeito de sua própria destinação histórica. Indivíduos manipulados e ludibriados não são capazes de colaborar para a transformação do mundo em sociedade justa, tanto aos oprimidos, quanto aos opressores. 
Como parte fundamental do processo dialógico da educação, a pedagogia freireana apresenta a práxis social. Vista pelo viés da humanização do humano, ela é a consequência da educação libertadora, comprometida com a transformação, tanto da escola, quanto da sociedade. Dessa forma, o papel mais importante do educador será ajudar aos educandos a compreender a realidade em que estão inseridos e, a partir da compreensão do real, buscar respostas concretas para problemas de inserção social e valorização profissional. Precisa-se dar um basta a todos quantos querem fazer o povo acreditar que a culpa por sua situação social injusta resulta da preguiça, da acomodação e outros mitos criados para justificar a injustiça e a exclusão social.

O sentido do conhecimento está em auxiliar na compreensão da realidade para o bem individual e comunitário. Esse processo dá a oportunidade para todos desfrutarem do conhecimento produzido e, consequentemente, atuarem na transformação de seu mundo. A educação libertadora tem o objetivo de realizar esse caminho de compreensão, uso e transformação do real para que ocorra a justiça social.

\section{Práxis social}

A práxis, na compreensão de Freire, está relacionada ao processo de libertação do oprimido. É um caminho construído entre o modo de ver o mundo e o modo de viver no mundo, como consequência da teoria que transforma o mundo. Pode-se dizer que, a práxis é um processo dialético entre teoria, reflexão e ação. Essa dinâmica traduz-se no compromisso entre o dito, o ensinado e a prática coerente que transforma o mundo. A educação dialógica traz em seu âmago a necessidade de compromisso entre o que se diz, pensa e realiza. Segundo Zitkoski,

[...] o diálogo implica uma práxis social, que é o compromisso entre a palavra dita e nossa ação humanizadora. Essa possibilidade abre caminhos para repensar a vida em sociedade, discutir sobre nosso ethos cultural, sobre nossa educação, a linguagem que praticamos e a possibilidade de agirmos de outro modo de ser, que transforme o mundo que nos cerca. (ZITKOSKI, 2008, p. 130).

A eficácia da educação libertadora situa-se na possibilidade de criar novas formas de viver e conviver, que transformam a sociedade em que os sujeitos do processo coexistem. Num primeiro momento, acontece a libertação da consciência do sujeito e, num segundo momento, esse mesmo sujeito passa a agir com liberdade e para a libertação social. Assim, o ensino como prática para a liberdade é uma forma de tornar-se sujeito da história, participante da comunidade e transformador da sociedade. No caso do educador, a possibilidade que se lhe abre é de, em conjunto com outros educadores e educandos, suscitar e participar do movimento de libertação, a partir de seu próprio contexto para a esfera global.

A práxis é uma maneira de sair da condição de "autodemitidos da vida", porque quem não pensa a sua própria história e não a faz acontecer, não participa nem do que acontece em sua própria vida e nem da vida coletiva. Nessa perspectiva, entende-se outro aspecto da educação dialógica, que Freire chama de "pensar certo" e o relaciona ao "fazer certo". A coerência entre o pensar e o fazer produz o verdadeiro processo de humanização e libertação dos seres humanos. A formação para o pensar crítico é necessidade premente, pois, 
[...] não há o diálogo verdadeiro se não há nos seus sujeitos um pensar verdadeiro. Pensar crítico. Pensar que, não aceitando a dicotomia mundo-homens, reconhece entre eles uma inquebrantável solidariedade. Este é um pensar que percebe a realidade como processo, que a capta em constante devenir e não como algo estático. (FREIRE, 2011, p. 114).

No contexto educacional contemporâneo, falta a educação para o pensar crítico e a problematização como formas de aprofundar o conhecimento. Assimilamse imagens, internalizam-se conceitos e procuram-se soluções imediatas. Acostuma-se à velocidade, ao acúmulo de informações não assimiladas, as quais são reproduzidas, muitas vezes, sem reflexão. A cultura da rapidez e da facilidade se instalou nas mentes. Constata-se no dia a dia, a incapacidade de pensar por si mesmo, de elaborar as informações recebidas e de processá-las transformando-as em convicções próprias. Vive-se a cultura da impessoalidade e já não se assumem responsabilidades pelo que se diz, se faz e se pensa. Nesse sentido, a educação dialógica pode ser uma resposta de enfrentamento a essa questão.

A incerteza conduz à investigação. Quando não se está certo de alguma coisa, vai-se à busca do conhecimento. No caso da educação problematizadora, é preciso pensar com o outro e educar para um pensar que pergunta, que se torna curioso. $\mathrm{O}$ pensar crítico e questionador opera sobre a realidade, transformando-a. É a dialética da ação-reflexão-ação. A partir do pensar reflexivo, os sujeitos se tornam conscientes de sua situação e podem partir para a mudança, ou melhoramento de sua realidade. "A práxis [...] é reflexão e ação dos homens sobre o mundo para transformá-lo. Sem ela, é impossível a superação da contradição opressor-oprimidos." (FREIRE, 2011, p. 52). Não ocorre transformação da realidade se não existir a práxis. Assim, compreende-se a necessidade da formação permanente do professor como sujeito da e para a práxis.

\section{Formação permanente dos professores}

$\mathrm{Na}$ compreensão freireana, a formação permanente é consequência do reconhecimento que o ser humano tem de sua finitude e incompletude. Tomando consciência de seu ser, finito e incompleto, busca, sempre, construir-se na história, para "ser mais". Essa concepção independe de ideologias, cursos de formação exigidos em leis e por gestores, mas da própria necessidade humana de fazer-se e refazer-se sempre de novo.

A educação é permanente não porque certa linha ideológica ou certa posição política ou certo interesse econômico o exijam. A educação é permanente na razão, de um lado, da finitude do ser humano, de outro, da consciência que ele tem de sua finitude. Mais ainda, pelo fato de, ao longo da história, ter incorporado à sua natureza não apenas saber que vivia, mas saber que sabia e, assim, saber que podia saber mais. A educação e a formação permanente se fundam aí. (FREIRE, 1993, p. 20).

Para além das políticas que incentivam a formação permanente dos docentes e dos alunos, está a compreensão da própria natureza humana que traz como essência a dialética entre o ser, o estar sendo e o vir a ser. Cada etapa da vida humana 
corresponde à necessidade de ser outro. "Quem age é, institui-se, manifesta-se, presentifica-se, é constante devir. O professor age como totalidade, ou seja, ele é visto e compreendido fundamentalmente não só pelo que é, mas também pelo que ensina." (NOGARO; NOGARO, 2012, p. 111). É da natureza do educador e da educação o ser sempre mais, construir-se permanentemente na história e na sociedade, por isso a premência da formação permanente, não como algo que vem de fora para dentro, mas como um movimento que nasce no interior do ser e expande-se para o fazer exterior.

Nesse sentido, entende-se a vocação ontológica do ser humano para a humanização que se edifica ao longo de cada vida humana. Formar-se é um processo que demanda força de vontade do próprio sujeito e não tanto processos exteriores. Embora, há que reconhecer, devem ser oferecidas ao ser humano as condições necessárias para seu desenvolvimento. E essas ocorrem através de políticas públicas de formação de professores, da valorização da profissão docente e das condições do ambiente escolar. $\mathrm{Na}$ ótica de Freire:

[...] a educação, como formação, como processo de conhecimento, de ensino, de aprendizagem, se tornou, ao longo da aventura no mundo dos seres humanos uma conotação de sua natureza, gestando-se na história, como a vocação para a humanização de que falo na Pedagogia do Oprimido e na Pedagogia da Esperança. (FREIRE, 1993, p. 20).

Educação e formação humana são entendidas como práticas permanentes porque o ser humano é um ser histórico-social e, como tal, depende das condições históricas para ser. Prova disso são a escravidão, o fundamentalismo, o determinismo, o neoliberalismo, entre outras formas de manipulação, que dominaram, e ainda controlam, milhares de seres humanos, que não se sentem capazes, ou não se dão conta de sua capacidade de romper as amarras, que os prendem a ideologias opressoras ${ }^{3} \mathrm{e}$, ao longo da história, desumanizam homens e mulheres.

A formação permanente está relacionada ao processo de aprender e ensinar, como realidades ontológicas ao ser humano e ações profundamente vinculadas uma a outra, como movimentos de um único ato. Ao mesmo tempo em que se aprende, também se ensina e vice-versa. A dinâmica do aprender e ensinar é intrínseca ao ser humano e à sua capacidade de em refazendo-se refazer a história, o seu próprio mundo de atuação e convivência, por isso, a indignação perante o fato de determinadas ideologias, historicamente arraigadas nas consciências, pregarem um determinismo e fatalismo históricos de que nada pode ser mudado.

Isto significa ser o ser humano, enquanto histórico, um ser finito, limitado, inconcluso, mas consciente de sua inconclusão. Por isso, um ser ininterruptamente em busca, naturalmente em processo. Um ser que tendo por vocação a humanização, se confronta, no entanto, com o incessante desafio da desumanização, como distorção daquela vocação. (FREIRE, 1993, p. 18).

O ser humano é um ser em busca, nunca acabado, sempre em construção e, nessa dinâmica, está também o mundo no qual se insere, e que pode ser feito e refeito a todo o momento. Enquanto existir vida, haverá a esperança de mudança. Somente 
diante da morte não se pode mudar nada. Assim, ser humano e mundo nunca chegam à perfeição total, mas estão num eterno vir a ser, em constante renovação, na busca e construção de novos saberes e formas de ser, de fazer-se e fazer as coisas. Dessa forma, se abre a possibilidade do "inédito viável", pois sempre há algo novo em cada relação que se estabelece entre o ensinar e o aprender.

"O professor não trabalha só com rotinas, há momentos em que precisa mobilizar saberes, resolver crises, criar, inventar e definir estratégias e isto vai muito além da formação técnica, constitui-se como dimensão da totalidade." (NOGARO; NOGARO, 2012, p. 113). É isso que os educadores encontram nas salas de aula, no contato com educandos, porque nem tudo é previsível, sempre ocorrerá algo inédito, que é viável para renovar a aventura do aprender, a esperança do ensinar, o novo que a cada dia faz educadores e educandos mais apaixonados pela arte de educar. No pensamento de Freire:

[...] foi exatamente porque nos tornamos capazes de dizer o mundo, de conhecer, de ensinar o aprendido e de aprender o ensinado, refazendo o aprendido, melhorando o ensinar. Foi exatamente porque nos tornamos capazes de dizer o mundo, na medida em que o transformávamos, em que o reinventávamos, que terminamos por nos tornar ensinantes e aprendizes. (FREIRE, 1993, p. 19).

A única possibilidade de admitir que o ser humano seja programado é de que ele é "programado para aprender", porque vive a dinâmica de se reinventar, de ser ensinante e aprendiz a todo instante. Nesse sentido, a formação enquanto processo permanente, deve sempre despertar nos sujeitos da aprendizagem a necessidade de buscar e conhecer o outro, seja ele, o outro ser humano, o ente a ser conhecido, o trabalho no conhecimento de si mesmo e tudo o que é diferente de si.

A dinâmica do ensino e da aprendizagem configura a cada dia um novo educador e faz com que o educando se descubra e redescubra. Por isso, não dá para admitir o cansaço que se cria em determinados círculos de educadores e estudantes, pois aprender nunca deveria tornar-se repetitivo, cansativo e frustrante. Aprender e ensinar fundem-se na arte de descobrir, de estar sempre em busca do inacabado. Por que consciente do inacabamento,

\section{[...] por isso mesmo em permanente busca, indagador, curioso em torno de si e de si no e com o mundo e com os outros; porque histó- rico, preocupado sempre com o amanhã, não se achasse, como con- dição necessária para estar sendo, inserido, ingênua ou criticamente, num incessante processo de formação. (FREIRE, 1993, p. 19).}

Chama a atenção que, para uma boa prática de ensino e aprendizagem, professores e professoras precisam buscar sua própria libertação e trabalhar na libertação junto com os educandos. Para isso, contam com o poder da palavra como instrumento essencial no processo de aprender e ensinar. Conforme Freire (2011, p. 155), o objetivo da educação problematizadora é "[...] ultrapassar o nível da 'consciência real', atingindo o da 'consciência possível". Tudo é possível de ser transformado, quando se refere às situações e práticas criadas pela humanidade. A primazia da vida sobre interesses efêmeros e a utopia por um mundo melhor, associados a uma práxis social condizente, 
definem-se como objetivos da educação libertadora. Para além do conhecimento e de uma boa metodologia, necessários a um bom professor, faz-se premente que haja sabedoria de vida, pois,

[...] o exercício da docência exige mais do que possuir conhecimento e saber aplicar técnicas pedagógicas. A condução de um grupo de alunos e desenvolvimento do trabalho pedagógico exige do professor capacidade de conhecer, aplicar, ressignificar conhecimento como também organizar e mobilizar os discentes para que aprendam. (NOGARO; NOGARO, 2012, p. 114).

Depreende-se, portanto, que a profissão docente necessita mais do que teorias e métodos, pois a vida dos educadores e estudantes não está formatada, programada, uma vez que é vida, sempre pode surpreender, refazer-se, movimentar-se. Muitas vezes, falta às escolas, em sua estrutura curricular e física, e aos docentes, em seu planejamento, o espaço à vida das pessoas inseridas no processo educativo. Esse espaço é essencial para a construção efetiva do conhecimento.

\section{A palavra como instrumento para dizer e aprender/ensinar o mundo}

A palavra, entendida como forma de comunicar-se, é o instrumento mais utilizado pelos educadores na tarefa de ensinar e aprender. Sabe-se que a palavra tem poder de edificar ou de destruir, tem força para deixar feliz ou prejudicar para sempre a quem a ouve. Fiori (1980, p. 20), ao referir-se à palavra enquanto criadora, destaca seu sentido, força e profundidade. Afirma que ela é palavra e ação; não é o termo que assinala arbitrariamente um pensamento que, por sua vez, discorre separado da existência. "Palavra que diz e transforma o mundo." Em linguagem teológica a palavra tem tamanha força que ela se torna pessoa, "carne", dá origem a um ser humano e divino. Fala-se também da palavra como de uma comida saborosa que traz alegria e exultação ao coração de quem a ingere. ${ }^{4}$ Independente de crenças, é importante ressaltar que a palavra traz em seu âmago a potencialidade de transformar uma realidade em outra.

A educação dialógica tem como fundamento a palavra, que pode se expressar no diálogo falado, na empatia estabelecida, ou não, entre os sujeitos da aprendizagem, na coerência do dito com o realizado e na consciência de ser no mundo alguém que diz o mundo. Na educação dialógica a palavra tem tanto valor que Freire (2011, p. 227) diz que na teoria dialógica da ação, em lugar de alguém que domina e alguém que é dominado têm-se "[...] sujeitos que se encontram para a pronúncia do mundo, para a sua transformação". Pode-se entender que a palavra pronunciada é capaz de transformar consciências e realidades. "O conhecimento tem que ser tal que o sujeito se transforme, e com isto seja capaz de transformar a realidade. Esta é a educação que interessa: formar novos mestres e não eternos discípulos." (VASCONCELLOS, 2005, p. 40). No processo de formação, todos se tornam sujeitos.

Para a arte de educar e educar-se não é possível estabelecer métodos e técnicas estáticas, porque educar envolve a vida, supõe o tornar-se humano, e a "[...] aventura humana tampouco tem uma rota marcada, nem se encontra sob a orientação de uma lei universal do progresso." (MORIN, 2003, p. 99). A tarefa educacional é complexa e 
exigente porque envolve sujeitos em constante formação e transformação. Não existe uma fórmula, tudo é uma construção que se dá na espontaneidade e no ajuste a certas regras, necessitando-se igualmente de uma dose de disciplina, necessária para o sucesso de qualquer empreendimento.

Na prática pedagógica é preciso uma nova orientação dos objetivos da educação, como por exemplo, a conscientização da necessidade de mudança, da evolução do pensamento e do estabelecimento de relações novas e duradouras. Conscientizar é ultrapassar a esfera da compreensão espontânea e chegar à esfera crítica, na qual a realidade se dá a conhecer e o ser humano assume uma atitude epistemológica. Essa atitude leva a penetrar na essência do objeto a ser conhecido. Imbernón (2009, p.34) afirma que: “[...] paradoxalmente, há muita formação e poucas mudanças", isso, talvez seja devido aos professores receberem formação e não serem protagonistas de sua formação, adotando atitudes passivas e não produzindo respostas concretas aos problemas.

O fazer-se sujeito da própria transformação exige rigorosidade, disciplina, tanto para o aluno, quanto para o professor, num processo de atribuir a si a necessidade de mudança, como uma prática necessária para chegar ao conhecimento. A necessidade da disciplina está implícita em qualquer ação humana. Sem esta não se pode esperar muito êxito, pois ela aponta para a responsabilidade diante do que se fala e faz, como condição fundamental para as relações estabelecidas. “[...] ensinar não é depositar pacotes na consciência vazia dos educandos.”(FREIRE, 1993, p. 63). Trata-se aqui tanto de educadores, quanto de educandos, quando recebem formação das mais variadas modalidades, mas não são capazes de produzir transformação.

A palavra como instrumento para dizer, construir o mundo, é essencial ao cotidiano dos sujeitos do ambiente educacional, seja qual for ele. Fiori (1980, p. 13) sustenta isso quando enfatiza que com a palavra, o homem se faz homem. "Ao dizer sua palavra, pois, o homem assume conscientemente sua essencial condição humana. E o método que lhe propicia essa aprendizagem comensura-se ao homem todo, e seus princípios fundam toda pedagogia, desde a alfabetização até os mais altos níveis do labor universitário." Aquele que é capaz de falar sobre o seu mundo, compreende sua própria realidade e o mundo. Nesse sentido, faz-se necessário estimular à participação, pois esta "[...] produz como efeitos o conhecimento, o domínio de relações e competências para interferir nos processos sociais.” (WEYH, 2011, p. 67). A formação está afeita a essa capacidade de dizer o seu próprio mundo, pois o mundo pronunciado pelos sujeitos já foi interpretado por eles, e por sua vez, transformado em conhecimento, em mundo de todos e para todos.

Dizendo a palavra o ser humano se faz humano, porque o que o distingue dos demais animais é a palavra, manifestada de diversas formas e associada a uma compreensão do mundo que é, também, diferente da dos seres irracionais. Ao expressar seu próprio pensamento " $[$...] de espectadores as pessoas passam a sujeitos comprometidos"(WEYH, 2011, p.67) e assumem, com comprometimento, a sua parte em tarefas para o bem comum.

A palavra, pronunciada pelos educadores e educandos, diz o seu próprio mundo, interpreta a sua realidade e responde às suas necessidades. Dessa forma, é possível compreender que o educador precisa tornar-se protagonista na escola e na 
sociedade. Há um silenciamento docente, uma ausência de voz dos professores na sociedade, fala-se por eles, por isso perderam espaço nas esferas públicas. Nóvoa defende que é preciso reforçar a dimensão pessoal e a presença pública dos professores:

Trata-se de construir um conhecimento pessoal (um autoconhecimento) no interior do conhecimento profissional e de captar o sentido de uma profissão que não cabe apenas numa matriz técnica ou científica. Toca-se aqui em qualquer coisa de indefinível, mas que está no cerne da identidade profissional docente. (NÓVOA, 2009, p. 22).

O indefinível é o que não está planejado e comprovado cientificamente, mas que está presente no dia a dia do fazer docente, em sua luta pelo primado da vida sobre as técnicas. A arte do conhecimento está associada ao comunicar, que ocorre na dinâmica do ensinar e do aprender, que são reinventados a cada dia, a cada sujeito, a cada dimensão do real, manifestada nas ações produzidas em conjunto, nos diferentes ambientes de ensino e aprendizagem. Dessa forma, não é possível programar tudo, é possível apenas apontar caminhos, sugestões que necessitam ser adequadas a cada manifestação de vida, nascida na busca de saber sempre mais e de ser sempre mais.

\section{Continuando a pensar}

A reflexão sobre a temática da formação de professores, pela sua complexidade, suscita, dúvidas, questionamentos, inseguranças e novos caminhos a respeito de sua necessidade. A partir do estudo percebem-se alguns indicativos que podem servir de auxílio para desenvolver uma educação libertadora através da práxis transformadora. Os autores estudados, sobretudo Freire, apontam para mudanças na compreensão da formação permanente dos educadores, bem como de novas concepções acerca das formas de conceber o conhecimento e de inserir os educandos nesse processo.

Os indicativos apontados falam da necessidade de compreender o mundo em que se vive, usufruí-lo para a promoção de vida digna e justa para todos e da imperiosa necessidade de transformar o mundo, através do conhecimento. Ao entender a educação como dialógica não se pode perder de vista que ela não é algo apenas teórico, mas está diretamente ligada à práxis social, ou à transformação do mundo em que vivem os sujeitos. Pode-se afirmar que a educação será libertadora, ou dialógica, somente se envolver essas duas dimensões da vida das pessoas em constante formação e transformação.

A formação permanente decorre da finitude do sujeito e da consciência que ele tem da necessidade de sempre se renovar, ser mais, aprender mais. A consciência do ser e do vir a ser move-o a buscar sempre mais e refazer-se a cada dia. Essa dinâmica é o que revigora a educação, tornando-a atrativa e esperançosa de que ainda é possível construir um mundo onde se consiga encontrar um lugar para cada um. Em um ambiente que permita o sujeito ser ele mesmo, é provável que ele possa dizer sua palavra, dizer o seu mundo, edificar-se e atender às suas necessidades sem depender de quaisquer ideologias para ter o lugar que é seu por natureza e pela essência de sua constituição ontológica. 


\section{Referências}

BRASIL. Parecer CNE/CP 9/2001. Publicado no Diário Oficial da União de 18/01/2002, Seção 1, p. 31.

FIORI, E. M. Aprender a dizer sua palavra. Prefácio à Pedagogia do Oprimido. In: FREIRE, P. Pedagogia do Oprimido. 50 ed. Rio de Janeiro: Paz e Terra, 2011.

FRANCA, L. O Método Pedagógico dos Jesuítas: o Ratio Studiorum: Introdução e Tradução. Rio de Janeiro: Agir, 1952.

FREIRE, N. Contribuições de Paulo Freire para a pedagogia crítica: "Educação emancipatória: a influência de Paulo Freire na cidadania global" ou "A influência de Paulo Freire na educação para a autonomia e a libertação". Revista Electrónica Teoría de La Educación. Educacion y cultura em la Sociedade de la Información. v. 10, No 3. Noviembre 2009. Disponível em: http://www.usal.es/teoriaeducacion. Acesso em: nov. 2014.

FREIRE, P. Conscientização. Teoria e prática da libertação: uma introdução ao pensamento de Paulo Freire. São Paulo: Moraes, 1980.

. Política e Educação: ensaios. São Paulo: Cortez, 1993.

. Pedagogia do Oprimido. 50 ed. Rio de Janeiro: Paz e Terra, 2011.

IMBERNÓN, F. Formação permanente do professorado: novas tendências. São Paulo: Cortez, 2009.

MORIN, E.; MOTTA, R.; CIURANA, É. R. Educar para a era planetária: o pensamento complexo como método de aprendizagem no erro e na incerteza humana. São Paulo: Instituto Piaget, 2003.

NOGARO, A.; NOGARO, I. Primeira Infância: espaço e tempo de educar na autora da vida. Erechim: Edifapes, 2012.

NÓVOA, A. Professores: imagens do futuro presente. Lisboa: Educa, 2009.

PIN, S. A. Educar o humano: construção do sujeito em Paulo Freire. Frederico Westphalen: Pluma, 2014.

VASCONCELLOS, C. S. Construção do Conhecimento: em sala de aula. São Paulo: Libertad, 2005.

WEYH, C. B. Educar pela participação: uma leitura político-pedagógica do Orçamento Participativo Estadual no município de Salvador das Missões/RS. Santo Ângelo: FURI, 2011.

ZITKOSKI, J. J. Diálogo/Dialogicidade. In: Dicionário Paulo Freire. Belo Horizonte: Autêntica, 2008. p. 130-131.

Notas

${ }^{1}$ Termos entre aspas ao longo do texto são termos usados por Paulo Freire, presentes nas obras utilizadas como referências.

${ }^{2}$ A "palavra" possui um sentido sui generis em Freire. Para orientar o entendimento do leitor, neste princípio de texto, vamos defini-la como forma de comunicar-se. É o instrumento mais utilizado por educadores e educadoras em sua tarefa de ensinar e aprender. Sabe-se que a palavra tem o poder de edificar ou de destruir, tem a força de deixar feliz ou de prejudicar para sempre a quem a ouve. Ao longo do texto, aparecerão outras compreensões que permitirão maior clareza sobre o sentido da mesma. 
${ }^{3}$ Veja-se, por exemplo, o caso da escravização dos negros, a ideologização dos índios e o extermínio de algumas de suas culturas pela dita civilização, ou, mais recentemente, os casos de linhas fundamentalistas religiosas.

${ }^{4}$ Segundo o Evangelho de João, capítulo 1, e Jeremias, capítulo 15.

* Mestre em Educação pela Universidade Regional Integrada do Alto Uruguai e das Missões, Frederico Westphalen, Rio Grande do Sul, Brasil.

** Professor doutor da Universidade Regional Integrada do Alto Uruguai e das Missões, Erechim, Rio Grande do Sul, Brasil.

*** Professor doutor da Universidade Regional Integrada do Alto Uruguai e das Missões, Santo Ângelo, Rio Grande do Sul, Brasil.

\section{Correspondência}

Silvana Aparecida Pin - Universidade Regional Integrada do Alto Uruguai e das Missões, URI Câmpus de Frederico Westphalen. Rua Assis Brasil, 782, Itapagé, CEP: 98400-000 - Frederico Westphalen, Rio Grande do Sul - Brasil.

E-mail: silvana.aparecidapin@gmail.com - narnaldo@uricer.edu.br - ceniow@santoangelo.uri.br

Recebido em 13 de maio de 2015

Aprovado em 12 de maio de 2016 
